\title{
Mechanically-induced grain coarsening in gradient nano-grained copper
}

\author{
W. Chen ${ }^{\mathrm{a}}$, Z.S. You ${ }^{\mathrm{a}, \mathrm{b}}$, N.R. Tao ${ }^{\mathrm{a}}$, Z.H. Jin ${ }^{\mathrm{c}, *}$ and L. Lu ${ }^{\mathrm{a}, *}$ \\ ${ }^{a}$ Shenyang National Laboratory for Materials Science, \\ Institute of Metal Research, Chinese Academy of Sciences, \\ 72 Wenhua Road, Shenyang 110016, People's Republic of China \\ ${ }^{\mathrm{b}}$ Herbert Gleiter Institute of Nanoscience, \\ Nanjing University of Science and Technology, \\ 200 Xiaolingwei Street, Nanjing 210094, People's Republic of China \\ ${ }^{\mathrm{C}}$ School of Materials Science and Engineering, \\ Shanghai Jiao Tong University, \\ 800 Dongchuan road, Shanghai 200240, People's Republic of China \\ *Corresponding authore-mail address: llu@imr.ac.cn; jinzh@sjtu.edu.cn
}

\begin{abstract}
:
Gradient nano-grained $\mathrm{Cu}$ subjected to tensile tests yields at a stress almost twice of that of the conventional coarse-grained $\mathrm{Cu}$ at or below the room temperature. Beyond the yield stress, a uniform plastic strain of larger than 30\% can be achieved, accompanied by homogeneous grain coarsening in nano-grained surface layer.The observed grain coarsening may induce certaindegree of "strain softening”. The measured grain coarsening rates strongly depend on temperature, stress and strain rate, suggesting that the grain coarsening is presumably limited by thermally activated dislocation activities at defective grain boundaries, rather than via diffusional process on atom-by-atom basis. A non-diffusional (source-limited) Mott-Turnbull rate equation has been proposed to interpret the observed grain coarsening phenomenon.
\end{abstract}

Keywords: Gradient nano-grained copper; Grain coarsening; Grain boundary migration; Non-diffusional kinetics; Deformation mechanisms 


\section{Introduction}

According to the well-known Hall-Petch relation[1,2], the strength of polycrystalline materials depends on grain size[3,4]. Nano-grained (NG) metals with grain size less than $100 \mathrm{~nm}$ usually exhibit high strength. However, with elevating temperature or by applying stress or strain, nano-grains tend to grow and the material strength tends to decrease. Softening due to grain coarsening or grain growth seems spontaneous and inevitable in many NG metals when the specimen is held at or even below the room temperature (RT)[5,6]. In particular, such "unusual” grain coarsening may occur more readily under mechanical deformation (termed as mechanically-induced grain coarsening), as observed in the indentation[7-9], rolling[10], compression[11] and tensile loading[12,13] tests. For example, it has been revealed that a gradient nano-grained (GNG) surface layer on a bulk coarse-grained (CG) pure $\mathrm{Cu}$ rod may sustain a tensile true strain exceeding $100 \%$ at $\mathrm{RT}$ accompanied by significant grain coarsening approaching to submicrometer levels[14].

Proper control of grain coarsening is essential to maintain the strengthening role of grain boundaries (GBs). Both thermal and mechanical events at GBs and within grains triggering grain boundary migration (GBM) must be taken into account in order to address the physical mechanisms underlying mechanically-induced grain coarsening. Among possible GB-based mechanisms, the shear-coupled GBM has been evidenced as a dominant one by both experimental observations [15-19] and a number of molecular dynamics simulations [20-25]: the normal motion of a GB is coupled to tangential displacement of adjacent grains results from an applied shear stress[26]. So far, only the role of stress on the GBM processes has been emphasized, whereas the elementary mechanisms occurring during the shear-coupled GBM are not yet well understood[27], in which temperature and strain-rate effects are still need to be addressed.

To understand the mechanism and general kinetics of the mechanically-induced grain coarsening, we have examined the mechanical behaviors of a GNG Cu layer on the surface 
of a bulk CG pure $\mathrm{Cu}$ rod (hereafter referred to as the GNG/CG $\mathrm{Cu}$ ) deformed at different temperatures and strain rates. With these samples, significant grain coarsening can be observed in the top NG layer under uniaxial tensile deformation and the rate of grain coarsening can be measured over a broad range of grain sizes at various strains or loading time. Besides, the softening due to grain coarsening can also be monitored at various temperatures and strain rates.

\section{Experimental}

\subsection{Sample preparation}

Commercial-purity $\mathrm{Cu}$ rods (99.97 wt.\%) consisting of well-annealed equiaxed coarse grains $(25 \mu \mathrm{m})$ were machined into dog-bone-shaped tensile samples with a gauge length of $20 \mathrm{~mm}$ and a gauge diameter of $6 \mathrm{~mm}$. Both the gauge sections and the arc transitions of the samples were subjected to surface mechanical grinding treatment (SMGT) following the procedure well described in[28]. The SMGT processing was repeated six times to obtain the top GNG layer of our samples.

\subsection{Tensile tests}

Uniaxial tensile tests of SMGT-processed Cu samples were performed on an Instron 5982 testing machine (Instron, UK) with a load capacity of $100 \mathrm{kN}$. An Instron 2620-601 clip-on extensometer was used to measure strain at RT (300 K), while an Epsilon model 3542 clip-on extensometer was used to measure strain at cryogenic temperature (123 K). To obtain each data set, at least three repeated tensile tests were carried out. The samples before and after tensile deformation were refrigerated at $258 \mathrm{~K}\left(-15^{\circ} \mathrm{C}\right)$. For comparison, CG Cu samples were also tested under the same conditions.

In order to estimate the strength of the top NG layer, the surface $20 \mu \mathrm{m}$ thick NG layers of the GNG/CG Cu were removed by electrolytic polishing. The samples without NG layers, hereafter referred to as the gradient ultra-fine grained (GFG) $\mathrm{Cu}$, were 
tensionedunder the same conditions for that of GNG/CG Cu. Based on the rule-of-mixture, i.e.,

$$
\sigma_{\mathrm{GNG} / \mathrm{CG}}=V_{\mathrm{NG}} \sigma_{\mathrm{NG}}+\left(1-V_{\mathrm{NG}}\right) \sigma_{\mathrm{GFG} / \mathrm{CG}}
$$

where $V_{\mathrm{NG}}$ is the volume fraction of the NG layer in the GNG/CG samples, $\sigma_{\mathrm{GNG} / \mathrm{CG}}, \sigma_{\mathrm{GFG} / \mathrm{CG}}$ and $\sigma_{\mathrm{NG}}$ are the strength of the GNG/CG $\mathrm{Cu}$, GFG/CG $\mathrm{Cu}$ and $\mathrm{NG} \mathrm{Cu}$ layer, respectively,the strength of the top surface NG layeras a function of plastic strain can be estimated by accurately measuring $\sigma_{\mathrm{GNG} / \mathrm{CG}}$ and $\sigma_{\mathrm{GFG} / \mathrm{CG}}$ from the tensile tests.

\subsubsection{Temperature}

Uniaxial tensile tests at $300 \mathrm{~K}$ and $123 \mathrm{~K}$ were carried out at a strain rate of $1 \times 10^{-2}$ $\mathrm{s}^{-1}$. GNG/CG samples were deformed to $\varepsilon_{\mathrm{T}}=5 \%$ and $25 \%$, then unloaded for further microstructural examination. To be consistent, all strains referred in this study are true strains. The tensile tests at $123 \mathrm{~K}$ were carried out in an Instron environmental chamber, which was cooled by pouring liquid nitrogen inside the chamber in a continuous flow. The temperature was controlled automatically by a $T$-type thermocouple temperature controller.

\subsubsection{Strain rate}

Four different strain rates, i.e. $1 \times 10^{-2} \mathrm{~s}^{-1}, 1 \times 10^{-3} \mathrm{~s}^{-1}, 1 \times 10^{-4} \mathrm{~s}^{-1}$ and $1 \times 10^{-5} \mathrm{~s}^{-1}$, have been used in our tensile tests. The microstructural evolutions of the GNG layer deformed at $1 \times 10^{-2} \mathrm{~s}^{-1}$ and $1 \times 10^{-5} \mathrm{~s}^{-1}$ were investigated further by scrutinizing their microstructure at strains of $\varepsilon_{\mathrm{T}}=5 \%, 15 \%$ and $25 \%$, respectively.

\subsection{Microstructural characterization}

The longitudinal sections of the SMGT Cu were examined by a FEI NanoSEM Nova 430 field emission gun scanning electron microscope (FEG-SEM). The microstructures of the top GNG surface layer before and after tensile deformation were examined by a JEOL-2010 transmission electron microscope (TEM) operated at a voltage of $200 \mathrm{kV}$. The grain size distributions of the top GNG Cu layer were measured using bright-field TEM images. Over 800 grains from about 60 TEM images were measured to determine the grain 
size distribution profile for each condition.

\section{Results}

\subsection{Microstructural characterization}

As-prepared SMGT Cu samples show shining surfaces with minor roughness $\left(R_{\mathrm{a}} \approx 0.3\right.$ $\mu \mathrm{m})$ and are crack-free. As shown in Fig. 1a, the specimen is characterized by a gradient structure composed of a GNG layer, a deformed CG layer and an undeformed CG core. The thickness of the mechanically treated surface layer in the radial direction is about $700 \mu \mathrm{m}$. TEM observations (Fig. 1b) indicate that almost equiaxed nano-sized grains (with an average transversal grain size of $\sim 42 \mathrm{~nm}$ ) are formed in the top surface layer of about 20 $\mu \mathrm{m}$ thick. Selected-area electron diffraction (SAED) patterns (inset in Fig. 1b) illustrate that the nano-grains have random crystallographic orientations. Both grains and curved or wavy GBs show up with high-level stress concentrations. They are highly defective, similar to those observed in nanostructured $\mathrm{Cu}$ prepared by other top-down approaches, such as dynamic plastic deformation[29]. Our observations suggest that the top GNG layer is definitely not dislocation-free; instead, nano-grains, GBs and dislocations must coexist although it is difficult to distinguish individual dislocations in this regime.

With depth going from $50 \mu \mathrm{m}$ down to $100 \mu \mathrm{m}$ (Figs. 1c and d), the average transversal grain size increases gradually from about 160 to $300 \mathrm{~nm}$. Most of these submicron-sized grains are delineated by distinct and sharp GBs. When the depth is down to about $700 \mu \mathrm{m}$, a regime consisting of typical dislocation tangles and dislocation cells shows up.

In this study, to examine the evolution of NG structures, we pay our attention mainly on the top NG surface layer ( $20 \mu \mathrm{m}$ thick) where the grain size is less than $100 \mathrm{~nm}$.

\subsection{Temperature effects}


True stress-strain curves from tensile tests at different temperatures are displayed in Fig. 2. It is found that GNG/CG Cu shows a yield strength ( $0.2 \%$ offset) almost twice of that of the CG sample. The increment in yield strength is mainly attributed to the strong GNG surface layer and deformed CG layer[14]. At lower temperatures, such as $123 \mathrm{~K}$, the measured yield strength of GNG/CG Cu is $149 \mathrm{MPa}$, almost $20 \mathrm{MPa}$ larger than that at 300 $\mathrm{K}$. In contrast, for the $\mathrm{CG} \mathrm{Cu}$, the measured strength at 123 Kincreases by a small amount, merely $7 \mathrm{MPa}$, comparing to that at $300 \mathrm{~K}$. The stronger temperature dependence observed for the GNG/CG Cu sample suggests that the GNG layer is capable of sustaining a higher tensile stress at lower temperatures before plastic deformation sets in. The behavior is similar to NG Cu, i.e., the hardness of NG Cu with grain size of about $11 \mathrm{~nm}$ may increase from 2.1 to 3.9 GPa when the temperature is decreased from RT to $123 \mathrm{~K}[30]$.

Comparing to the microstructure in as-SMGT states (Fig. 1b), obvious grain coarsening and reduction in dislocation density are found in the top NG Cu layer after tensile testing at $300 \mathrm{~K}$ (Figs. 3a and b). Grain coarsening is also detected in the NG layer if the tensile test is carried out at $123 \mathrm{~K}$ (Figs. 3c and d). However, up to a certain strain, the extent of grain coarsening is less significant and a much higher density of dislocations is retainedat $123 \mathrm{~K}$, underlying that the recovery effects associated with dislocations and GBs can be suppressed at low temperatures[31]. A higher dislocation densitycan be observed in the small grains compared to thelarger ones in the top NG layer after tensioned to a certain strain.In different grains, different dislocation density also underlies different levels of stress.The grain coarsening processes also modify the GB morphology appreciably. Accompanying grain coarsening, more and more straight and sharp GBs appear at $300 \mathrm{~K}$ (Figs. 3a and b). The situation is less evident for the low temperature case (123 K, Figs 3c and d), suggesting that the GBs after low temperature deformation remain defective to certain degrees.

Grain size distributions in the top NG Cu layer at different temperatures and strains 
have been determined, in terms of the area-weighted cumulative distribution profile, which represents the proportion of the area fraction of grains smaller than a certain given size. As summarized in Fig. 4, comparing to the relatively narrow grain size distribution of the as-SMGT $\mathrm{Cu}\left(\varepsilon_{\mathrm{T}}=0 \%\right)$, the profiles become broader with increasing strain at both $123 \mathrm{~K}$ and $300 \mathrm{~K}$. However, at given strains, i.e. $\varepsilon_{\mathrm{T}}=5 \%$ and $25 \%$, the low-temperature profiles always lie on the left-hand side of the corresponding high-temperature profiles, acting as a direct evidence that grain coarsening upon tensile deformation is sensitive to thermal activation: the lower the temperature, the slower the grain coarsening rate.

\subsection{Strain-rate effects}

Grain coarsening in the GNG/CG sample also depends on strain rate. Fig. 5 displays the true stress-strain curves measured under various strain rates, ranging from $1 \times 10^{-5}$ to 1 $\times 10^{-2} \mathrm{~s}^{-1}$ at $300 \mathrm{~K}$. With increasing strain rate, the yield stress is elevated from 119 to 129 $\mathrm{MPa}$ for the GNG/CG $\mathrm{Cu}$, whereas the strain-rate dependence for the $\mathrm{CG} \mathrm{Cu}$ is almost negligible. Such behavior, i.e., the larger the strain rate, the higher the yield strength, again, is similar to that of NG Cu. The NG Cu also shows a stronger strain-rate sensitivity than the CGsample as observed in previous studies[32].

Grain coarsening readily occurs under different strain rates, as shown in Fig. 6. At given strains $\left(\varepsilon_{\mathrm{T}}=15 \%\right.$ and $25 \%$, respectively), grain coarsening at lower strain rate $(1 \times$ $10^{-5} \mathrm{~s}^{-1}$, Figs. 6e and $\left.\mathrm{f}\right)$ turns out to be more significant than that at higher strain rate $(1 \times$ $10^{-2} \mathrm{~s}^{-1}$, Figs. $6 \mathrm{~b}$ and c). As evidenced more quantitatively by grain-size distribution profiles corresponding to different strains under different strain rates, as shown in Fig. 7a, the distribution profiles show significant shifts toward larger grain sizes for the low strain-rate case $\left(1 \times 10^{-5} \mathrm{~s}^{-1}\right)$, comparing to those for the high strain-rate case $\left(1 \times 10^{-2} \mathrm{~s}^{-1}\right)$. The present results indicate that the top NG Cu layer may show stronger stability with increasing the strain rate, indicating that high strain rate and low temperature (Figs. 4 and 
7a) may play similar roles in prohibiting the grain coarsening of the NG $\mathrm{Cu}$.

Further, we normalized the $x$-axis of Figs. 4 and 7a with the mean grain sizes, as shown in Fig. 7b. Obviously, the grain size distribution curves of the top surface layer atdifferent temperatures and strain rates exhibit a single monotonic curve and overlap with that of the as-prepared NG layer, indicating that the grain coarsening of all samples occur in a self-similar manner, rather thanexhibiting a bimodal behavior. The above results further confirm that the grain coarsening process of the NG $\mathrm{Cu}$ layer on a gradient substrate isuniform and homogeneous,in contrast to the abnormal grain coarseningobserved in the free-standing NG metals under thermal [5] or mechanical loads[12].

\section{Discussion}

The microstructural evolution dominated by grain coarsening at the top NG layer has been examined under various experimental conditions. Grain coarsening can be enhanced either by increasing the temperature or by reducing the strain rate. Clearly, mechanically-induced grain coarsening or associated GBM in the top NG layer is not merely stress-driven; thermal activationisalso closelyrelevant.In following sections, the influence of grain coarsening on the tensile properties of GNG/CG $\mathrm{Cu}$ will be discussed first. Thenwe proposed anempirical kinetic equation to account the roles of stress and temperature on the mechanically-induced coarsening of nanoscale grains.

\subsection{Grain coarsening and strain softening}

To quantify the effect of grain coarsening on the tensile properties, one needs to determine the flow stress of the surface NG layer as a function of strain. For such purpose, the true stress-strain curves of the GNG/CG and GFG/CG samplesare measured and compared in Fig. 8a. Based on the stress differences between the GNG/CG and GFG/CG samples, the stress-strain curve of NG layer is estimated in Fig. 8b.The yieldstrength of NG 
layer at $300 \mathrm{~K}$ and $1 \times 10^{-5} \mathrm{~s}^{-1}$, about $620 \mathrm{MPa}$, isconsistent with those obtained forfree-standing NG Cu layers[14]. Clearly, a continuous strain softening beyond plastic yielding takes place in the NG layers during tensile deformation. Such softening effectscanalso be confirmed by the microhardness measurements, where the hardness monotonically decreasesas strainincreases[33].

The estimated flow stressesofthe NG layers at different strains (as indicated by the open symbols in Fig. 8b)can be plotted as a function of the inverse square root of the corresponding grain size $\left(d_{t}^{-1 / 2}\right.$, determined from Figs. 4 and 7a). As shown in Fig. 9, the stresses follow a "Hall-Petch"-like relation at a constant slope $(k)$ of $\sim 0.11 \mathrm{MPa} \mathrm{m}^{1 / 2}$ under different deformation conditions. The slopeagrees with previously deduced data for a number of NG Cu samples[32,34]. Such analyses identify that the flow stress of our GNG/CG samplesobey very well theHall-Petchrelationwhen grain coarsening proceeds.

The deformation mechanism induced strain softening in NG pure Cu layer of this study is different from the geometry necessary dislocations induced extra strain hardening in gradient surface nano-crystallized (SNC) IF steel [35,36] and SNC $\mathrm{Cu}[37]$. The major difference between extra strain hardening and strain softening lies in the grain coarsening. No grain coarsening phenomena was observed or reported, either in SNC IF steel[35] or $\mathrm{SNC} \mathrm{Cu}[37]$. In contrary, our investigations demonstrate obvious grain coarsening in the surface NG $\mathrm{Cu}$ layer. This mechanically-inducedGBM process with a substantial concomitant grain coarsening dominates plastic deformation of the GNG structure and inevitably inducescertain degree of "strain softening”.

In addition, even if in the SNC samples without concurrent grain coarsening, the extra strain hardening of surface NG layer in the gradient structure is still very limited. For example,the hardness increment due to the extra strain hardening is less than $2 \%$ in the top $\sim 25 \mu \mathrm{m}$ thick layer of SNC IF steel at a strain of $25 \%$ [35], and even smaller than $1 \%$ in the top $\sim 100 \mu \mathrm{m}$ thick layer of SNC Cu at a strain of $12 \%$ [37]. In contrary, as shown in Figs. 8b 
and 9, when the GNG/CG Cu tensioned to $\varepsilon_{\mathrm{T}}=25 \%$, there is about $40 \%$ decrease in the strength of the top NG layer accompanied with significant grain coarsening.

As discussed above, the strain softening induced by grain coarsening, rather than extra strain hardening, acts as the dominatingdeformation mode for the top NG layer of GNG/CG $\mathrm{Cu}$. The Hall-Petch type plots in Fig. 9, whichprovides usefully an unambiguous relation between the stress and grain size, can be considered as one set of experimental evidences to support our conclusion.

\subsection{Diffusional-limited grain coarsening kinetics}

To address grain coarsening kinetics by including the stress, temperature and strain-rate dependences, it is essential to measure the coarsening rate of the surface NG layer, which can be done by plotting the average grain size as a function of deformation duration, as shown in Fig. 10. The nominal velocity represents the average migration rate for all the GBs. It is justified since grain coarsening in the surface NG layer can be treated as steady-state and homogeneous. From Fig. 10, the coarsening rate is about $1.426 \mathrm{~nm} \mathrm{~s}^{-1}$ at $300 \mathrm{~K}$ under the strain rate of $1 \times 10^{-2} \mathrm{~s}^{-1}$. With decreasing the temperature to $123 \mathrm{~K}$, the coarsening rate turns out to be about $0.874 \mathrm{~nm} \mathrm{~s}^{-1}$. In contrast, the grain coarsening slows down by almost three orders of magnitude, i.e. $0.003 \mathrm{~nm} \mathrm{~s}^{-1}$, as the tensile test is carried out at a much-lower strain rate, i.e. $1 \times 10^{-5} \mathrm{~s}^{-1}$ at $300 \mathrm{~K}$.

To understandthe observed grain coarsening rates, we first consider the conventional diffusional-limited GBM model. According to Mott and Turnbull[38,39], the thermally activated GBM rate can be expressed as

$$
v=v_{0} \exp \left[-Q_{\mathrm{GB}} / k_{\mathrm{B}} T\right]
$$

where $Q_{\mathrm{GB}}$ represents the free energy barrier opposing GBM and has been found to be closely relevant to self-diffusion of GB atoms[38,39], and $v_{0}$ is a characteristic rate at which a GB tends to move without any need to jump over an energy barrier $\left(Q_{\mathrm{GB}}=0\right)$. By taking 
$Q_{\mathrm{GB}} \approx 1 \mathrm{eV}$ for $\mathrm{Cu}$ [31], with Eq. (2), the extrapolated GBM rate drops from $10^{-4} \mathrm{~nm} \mathrm{~s}^{-1}$ at $300 \mathrm{~K}$ down to $10^{-35} \mathrm{~nm} \mathrm{~s}^{-1}$ at $123 \mathrm{~K}$, tens of orders of magnitude smaller than our measureddata, $\sim 10^{-3} \mathrm{~nm} \mathrm{~s}^{-1}$. Therefore, the conventional model [40] is not readily applicable as long as $Q_{\mathrm{GB}}$ is treated as constant and stress-independenton the basisthat GBM is merely diffusional-limited.

The stress dependence was previously includedthrough the prefactor $v_{0}$ in Eq. (2)as a linear function of $\sigma[41,42]$. Accordingly, the GBM kinetics can be described as

$$
\nu=M(T) \sigma=M_{0} \exp \left[-Q_{\mathrm{GB}} / k_{\mathrm{B}} T\right] \sigma
$$

where $M_{0}$ is a measure of GB mobility. Again, such a model is incapable of describing our data because the GBM rate at RT may change by three orders of magnitude depending on the strain rates, but the stress merely varies by $20 \%$, as shown in Fig. $8 \mathrm{~b}$. If $v_{0}$ is treated as a linear function of the strain rate regardless of the stress, one would have a situation similar to Eq. (2), the low-temperature (123 K) and high-temperature (300 K) migration rates cannot be treated in a consistent manner.

\subsection{Mechanically-induced grain coarsening kinetics}

To describe the grain coarsening kinetics by including both thermal and mechanical effects, an alternative formula can be adopted

$$
v(\sigma, T)=v_{0} \exp \left[-Q_{\mathrm{GB}}(\sigma) / k_{\mathrm{B}} T\right]
$$

where the activation free energy $Q_{\mathrm{GB}}(\sigma)$ is treatedexplicitly stress-dependent: at zero applied stress, $Q_{\mathrm{GB}}$ is maximum; at a critical stress $\sigma_{0}, Q_{\mathrm{GB}} \mathrm{is}$ essentially zero. Hence, the relation between $Q_{\mathrm{GB}}$ and $\sigma$ can be taken as a power-law function $[43,44]$

$$
Q_{\mathrm{GB}}(\sigma)=Q_{0}\left(1-\sigma / \sigma_{0}\right)^{P}
$$

To demonstrate Eq. (4) is applicable to interpret our measured velocity data we need following considerations in order to assign reasonable values to parameters $Q_{0}, \sigma_{0}$ and $P$ in Eq. (5). 
(i) The parameter $Q_{0}$. The number $Q_{0}$ is a measure of the activation energy without stress assistance $(\sigma=0)$. Such values may range from $1 \mathrm{eV}$ to more than $20 \mathrm{eVs}$ depending on the structure of the symmetrical GBs for $\mathrm{Cu}$ [45].Defect contents at GB or dislocations in close proximity of GBs may significantly decrease this number to about $1 \mathrm{eV}[46]$.For general considerations, the value of $Q_{0}$ is taken to be $1 \mathrm{eV}$ in this study.

(ii) The parameter $\sigma_{0}$. The number $\sigma_{0}$ measures the critical stress at which the GBM becomes spontaneous because the migration energy barrier is essentially zero at $\sigma_{0}$. This value can be taken to be the measured maximum strength of $\mathrm{NG} \mathrm{Cu}(\sim 11 \mathrm{~nm})$ at liquid-nitrogen temperature[30], i.e. 1.5 GPa in our case.

(iii) The parameter $P$. The index number $P$ measures how strongly the activation energy decreases as a function of the applied stress.In general, such tendency is measured by the activation volume, defined by $V^{*}(\sigma)=-\partial Q(\sigma) /\left.\partial \sigma\right|_{\sigma}$. When $P$ is taking to be 2 and 3 , with $Q_{0}=1 \mathrm{eV}, \sigma_{0}=1.5 \mathrm{GPa}$ and $\sigma=0.9 \mathrm{GPa}$, the calculated $V^{*}$ is about $9 b^{3}$ and $5 b^{3}$, respectively.These calculated $V^{*}$ is consistent with the experimental measured data of NG $\mathrm{Cu}$, which is roughly $10-20 b^{3}[32,47]$.

With the above considerations, we demonstrate the GBM ratesin Fig. 11a as a function of stress at temperatures 123 Kand 300 Kpredicted according to Eq. (4) and Eq. (5), with parameters $Q_{0}=1 \mathrm{eV}, \sigma_{0}=1.5 \mathrm{GPa}$ and $P=2.8$. The theoreticalmodelcan capture both the stress and temperature dependences of our measured data at different strain rates and temperatures, showing almost the same pre-exponential velocity parameters $v_{0}$, which are about $100-150 \mathrm{~nm} \mathrm{~s}^{-1}$.

With this theoretical model, the predicted activation energy and activation volume as functions of stress show similar trends (Figs. 11b and c), i.e., they both decrease with increasing the applied stress. That is, the higher the stress, the smaller the activation energy barrier and activation volume become, and the faster the GBs migrate. The low activation energies induced by high applied stress can explain the observations of rapid 
mechanically-induced grain coarsening with limited thermal activation at low temperatures.

\subsection{Mechanically-induced vs. diffusional-limited grain coarsening kinetics}

Besides the stress dependence of the activation energy, the major difference between Eq. (4) and Eq. (2) is the pre-exponential factor, $v_{0}$, a characteristic rate at which a GB tends to move without any need to jump over an energy barrier $\left(Q_{\mathrm{GB}}=0\right)$. Such jumping events can be viewed as alignment of GB atoms by following the lattice orientation of the growing grain. Particularly, one may wonder how many GB atoms need to be involved to promote the GB motion by a certain distance within a certain time. With such considerations, one may confront at least two entirely different scenarios.

(i) The GB appears to be "viscous" and unable to carry significant shear, a situation in particular true at high temperatures. All GB atoms show the same probability to align themselves such that the entire GB may migrate in a "continuous" fashion. One may call such process the "diffusional-limited grain coarsening”, featured by almost stress-independent $Q_{\mathrm{GB}}$ and relatively large coarsening rate. Eq. (2) can assemble such features. Since $Q_{\mathrm{GB}}$ can be much larger than $k_{\mathrm{B}} T$, the pre-exponential factor $v_{0}$ may show up as an extremely large number.

(ii) The GB appears to be "rigid" and capable to resist shear, a situation in particular true at low temperatures. The GB atoms have to be forced to displace in order to trigger the GBM. Such “mechanically-induced grain coarsening”processis featured by strongly stress-dependent $Q_{\mathrm{GB}}$. Because $\mathrm{GBM}$ only occurs when $Q_{\mathrm{GB}}$ approaches to $k_{B} T$, as assembled by Eq. (4), the pre-exponential factor $v_{0}$ is unnecessarily large. Furthermore, it allows that GBM occurs locally if stress concentration is built up preferentially over there, especially due to the presence of lattice dislocations.

To reveal the trend that thermal activations of dislocation activities, either within grains or at GBs, accounts for the low-temperature grain coarsening, one may 
mapgrain-coarsening rates measured for different metals [13,48-62] as a function of reduced temperature into a single plot. As illustrated in Fig. 12, the data seemingly fall into two well-separated zones: A high-temperature zone ( $\left.\mathrm{T}>1 / 3 T_{\mathrm{m}}\right)$ demonstrating a trend following Eq. (2) and a low-temperature zone ( $\mathrm{T}<1 / 3 T_{\mathrm{m}}$ ) featured by Eq. (4). With increasing the temperature, diffusion-limited GB activities may be enhancedfor most metals, featured by a narrow zone manifestedby an almost constant reduced transition temperature, i.e., one-third of melting point $\left(T \approx 1 / 3 T_{\mathrm{m}}\right)$. Such behavior supports that the activation energy barrier for GB diffusioncan be roughly treated as a linear function of $T_{\mathrm{m}}$ with negligible stress dependence[31,63]. On the other hand, the broader zone at the low-temperature regime underlies that the grain coarsening kinetics featured by Eq. (4) show a much stronger martial-dependent than Eq. (2).

\subsection{Mechanically-induced grain coarsening kinetics-further issues}

Both the strength and the ductility depend on the existence of dislocations and GBs in $\mathrm{Cu}$. When grain size $(d)$ changes from millimeters to nanometers, three grain-size regimes can be identified[64]: regime $\mathrm{I}, \mathrm{d}>10^{3} \mathrm{~nm}$, dislocation activities dominate; regime $\mathrm{II}, \mathrm{d} \approx$ $10^{3}-10 \mathrm{~nm}$, dislocations are mostly restricted to their slip planes; and regime III, $\mathrm{d}<10 \mathrm{~nm}$, lattice dislocations are absent so GB activities and the reverse Hall-Petch relation play essential roles. In terms of the flow stress, it is believed that in regimes I and II grain-size hardening occurs and the Hall-Petch relation applies.

In particular, we found that the transition from regime II to I occurs in the GNG layer accompanied by grain-size softening of GNG layer. Such softening has nothing to do with that in regime III but obeys the normal Hall-Petch relation along with grain coarsening (Fig. 9), underlying that dislocations are no longer restricted at their glide planes but tend to trigger the motion of GBs and/or gain extra space for their own motion. In contrast to the deformation process in regime I where the mechanism is closely related to the intersection 
of dislocations, in regime II the GBM (GB shear) is promoted by pileup of dislocations and the interaction between dislocations and GBs. In both regimes, the plastic activities are rate-controlled, instead of being driven by the applied stress alone.

WithEq. (4) and Eq. (5), both the applied stress and temperature dependences can be included if the GBM kinetics is addressed in terms of nucleation and propagation of GB defects resembling dislocation characteristics such as GB dislocations or disconnections[18,27,65-67]. Comparing to atomic jumping or shuffling events along GBs at high temperatures or under different driving forces [68], stress-dependent atomic motions promoted by propagation of GB dislocations or disconnections[69] can be considered as plausible mechanisms at low temperatures. The motion of GB disconnections in GB planes as an effective mode to trigger GBM has been demonstrated in recent works via molecular dynamics simulations[27] as well as evidenced experimentally via in-situ TEM observations[18,66].It is also worth noting that rearrangement of groups of atoms in asymmetric high-angle GB (or general GB) region may also require an applied driving force (strain/stress). The process requires essentially no GB dislocations or GB disconnections because they are not well defined for such GBs[70,71]. Such processes cannot be excluded to understand the source-limited GBM phenomena in our GNG $\mathrm{Cu}$ samples.

The rate-controlled mechanism seems not only useful to address the grain coarsening normally observed in a variety of NG samples under mechanical deformation [12,13], but also provide further clues to understand the abnormal grain coarsening at low temperatures without mechanical loading [5,6].To optimize the mechanical performance of NG materials, e.g. in terms of the trade-off between strength and ductility, it is essential to stabilize the NG structure at elevated temperatures. To this end, a delayed transition from "source-limited” to “diffusional-limited” grain coarsening beyond certain temperature limit, therefore, is highly desirable. 


\section{Summary and conclusions}

Microstructuralevolution at the top layer of GNG $\mathrm{Cu}$ has been examined under conditions of varioustemperatures and strain rates. The deformation was found to be dominated by grain coarsening, withsignificant "strain softening" at all deformation conditions considered. Although the strength isreduceddue to grain coarsening, the GNG $\mathrm{Cu}$ layerbecomes capable of accommodating massive plastic strain. As such, excellent plasticity of the entire specimen can be achieved.

At given strains, the grain coarsening tends to be enhanced at elevated temperatures and/or reduced strain rates, underlying that the grain coarsening is not exclusively controlled by the stress, but also thermally activated.To address the grain coarseningkinetics, an empirical source-limited kinetic equation has been proposedbyincorporating both thermal effect and stress dependence. The new set of equations is useful to understand the low-temperaturegrain coarsening kinetics according to our analyses. Our results provide strong evidence that the intrinsic mechanism underlying grain coarseningkinetics is stress-driven, thermally activated and largely source-limited, in particular,at low temperatures.

\section{Acknowledgements}

The authors acknowledge financial support from the National Basic Research Program of China (973 Program, 2012CB932202), the National Science Foundation of China (Grant Nos. 51420105001, 51171181, 51371171, 51471172 and 51401211), the Key Research Program of Frontier Sciences, CAS. The authors thank Mr. X. Si for SMGT sample preparation. Discussions with Profs. H.J. Gao, T. Zhu and X.Y. Li and instructive suggestions fromD.A. Molodov, G. Gottstein, H. Gleiter and P. Gumbsch are gratefully acknowledged. 


\section{References}

[1] E.O. Hall, The deformation and ageing of mild steel: III discussion of results, Proc. Phys. Soc. Sect. B 64 (1951) 747-753.

[2] N.J. Petch, The cleavage strength of polycrystals, J. Iron Steel Inst. 174 (1953) 25-28.

[3] M.A. Meyers, A. Mishra, D.J. Benson, Mechanical properties of nanocrystalline materials, Prog. Mater. Sci. 51 (2006) 427-556.

[4] J.R. Greer, J.T.M. De Hosson, Plasticity in small-sized metallic systems: intrinsic versus extrinsic size effect, Prog. Mater. Sci. 56 (2011) 654-724.

[5] V.Y. Gertsman, R. Birringer, On the room-temperature grain growth in nanocrystalline copper, Scripta Metall. Mater. 30 (1994) 577-581.

[6] W. Chen, Z.S. You, N.R. Tao, L. Lu, Microstructural evolutions and stability of gradient nano-grained copper under tensile tests and subsequent storage, IOP Conf. Ser.: Mater. Sci. Eng. 89 (2015) 012001.

[7] K. Zhang, J.R. Weertman, J.A. Eastman, The influence of time, temperature, and grain size on indentation creep in high-purity nanocrystalline and ultrafine grain copper, Appl. Phys. Lett. 85 (2004) 5197-5199.

[8] M. Jin, A.M. Minor, E.A. Stach, J.W. Morris Jr., Direct observation of deformation-induced grain growth during the nanoindentation of ultrafine-grained $\mathrm{Al}$ at room temperature, Acta Mater. 52 (2004) 5381-5387.

[9] K. Zhang, J.R. Weertman, J.A. Eastman, Rapid stress-driven grain coarsening in nanocrystalline $\mathrm{Cu}$ at ambient and cryogenic temperatures, Appl. Phys. Lett. 87 (2005) 061921.

[10]N.P. Gurao, S. Suwas, Deformation mechanisms during large strain deformation of nanocrystalline nickel, Appl. Phys. Lett. 94 (2009) 191902.

[11]D. Pan, S. Kuwano, T. Fujita, M.W. Chen, Ultra-large room-temperature compressive plasticity of a nanocrystalline metal, Nano Lett. 7 (2007) 2108-2111.

[12]D.S. Gianola, S. Van Petegem, M. Legros, S. Brandstetter, H. Van Swygenhoven, K.J. Hemker, Stress-assisted discontinuous grain growth and its effect on the deformation behavior of nanocrystalline aluminum thin films, Acta Mater. 54 (2006) 2253-2263.

[13]G.J. Fan, L.F. Fu, H. Choo, P.K. Liaw, N.D. Browning, Uniaxial tensile plastic deformation and grain growth of bulk nanocrystalline alloys, Acta Mater. 54 (2006) 4781-4792.

[14]T.H. Fang, W.L. Li, N.R. Tao, K. Lu, Revealing extraordinary intrinsic tensile plasticity in gradient nano-grained copper, Science 331 (2011) 1587-1590.

[15]T. Gorkaya, D.A. Molodov, G. Gottstein, Stress-driven migration of symmetrical $<10$ $0>$ tilt grain boundaries in Al bicrystals, Acta Mater. 57 (2009) 5396-5405.

[16]T. Gorkaya, K.D. Molodov, D.A. Molodov, G. Gottstein, Concurrent grain boundary motion and grain rotation under an applied stress, Acta Mater. 59 (2011) 5674-5680.

[17]T. Gorkaya, T. Burlet, D.A. Molodov, G. Gottstein, Experimental method for true in situ measurements of shear-coupled grain boundary migration, Scripta Mater. 63 (2010) 
633-636.

[18]A. Rajabzadeh, M. Legros, N. Combe, F. Mompiou, D.A. Molodov, Evidence of grain boundary dislocation step motion associated to shear-coupled grain boundary migration, Philos. Mag. 93 (2013) 1299-1316.

[19]D.A. Molodov, T. Gorkaya, G. Gottstein, Dynamics of grain boundaries under applied mechanical stress, J. Mater. Sci. 46 (2011) 4318-4326.

[20]J.W. Cahn, Y. Mishin, A. Suzuki, Coupling grain boundary motion to shear deformation, Acta Mater. 54 (2006) 4953-4975.

[21]D. Farkas, A. Froseth, H. Van Swygenhoven, Grain boundary migration during room temperature deformation of nanocrystalline Ni, Scripta Mater. 55 (2006) 695-698.

[22]V. Dupont, F. Sansoz, Quasicontinuum study of incipient plasticity under nanoscale contact in nanocrystalline aluminum, Acta Mater. 56 (2008) 6013-6026.

[23]E.R. Homer, S.M. Foiles, E.A. Holm, D.L. Olmsted, Phenomenology of shear-coupled grain boundary motion in symmetric tilt and general grain boundaries, Acta Mater. 61 (2013) 1048-1060.

[24]M. Velasco, H. Van Swygenhoven, C. Brandl, Coupled grain boundary motion in a nanocrystalline grain boundary network, Scripta Mater. 65 (2011) 151-154.

[25]J. Schäfer, K. Albe, Competing deformation mechanisms in nanocrystalline metals and alloys: coupled motion versus grain boundary sliding, Acta Mater. 60 (2012) 6076-6085.

[26]D. Caillard, F. Mompiou, M. Legros, Grain-boundary shear-migration coupling. II. Geometrical model for general boundaries, Acta Mater. 57 (2009) 2390-2402.

[27]A. Rajabzadeh, F. Mompiou, M. Legros, N. Combe, Elementary mechanisms of shear-coupled grain boundary migration, Phys. Rev. Lett. 110 (2013) 265507.

[28]W.L. Li, N.R. Tao, K. Lu, Fabrication of a gradient nano-micro-structured surface layer on bulk copper by means of a surface mechanical grinding treatment, Scripta Mater. 59 (2008) 546-549.

[29]Y.S. Li, N.R. Tao, K. Lu, Microstructural evolution and nanostructure formation in copper during dynamic plastic deformation at cryogenic temperatures, Acta Mater. 56 (2008) 230-241.

[30]Z. Huang, L.Y. Gu, J.R. Weertman, Temperature dependence of hardness of nanocrystalline copper in low-temperature range, Scripta Mater. 37 (1997) 1071-1075.

[31]G. Gottstein, L.S. Shvindlerman, Grain boundary migration in metals: thermodynamics, kinetics, applications, CRC press, Bota Raton, 1999.

[32]J. Chen, L. Lu, K. Lu, Hardness and strain rate sensitivity of nanocrystalline Cu, Scripta Mater. 54 (2006) 1913-1918.

[33]T.H. Fang, N.R. Tao, K. Lu, Tension-induced softening and hardening in gradient nanograined surface layer in copper, Scripta Mater. 77 (2014) 17-20.

[34]P.G. Sanders, J.A. Eastman, J.R. Weertman, Elastic and tensile behavior of nanocrystalline copper and palladium, Acta Mater. 45 (1997) 4019-4025.

[35]X. Wu, P. Jiang, L. Chen, F. Yuan, Y.T. Zhu, Extraordinary strain hardening by gradient structure, Proc. Natl. Acad. Sci. 111 (2014) 7197-7201.

[36]J. Li, S. Chen, X. Wu, A.K. Soh, A physical model revealing strong strain hardening in nano-grained metals induced by grain size gradient structure, Mater. Sci. Eng. A 620 (2015) 
$16-21$.

[37]X.C. Yang, X.L. Ma, J. Moering, H. Zhou, W. Wang, Y.L. Gong, J.M. Tao, Y.T. Zhu, X.K. Zhu, Influence of gradient structure volume fraction on the mechanical properties of pure copper, Mater. Sci. Eng. A 645 (2015) 280-285.

[38]N.F. Mott, Slip at grain boundaries and grain growth in metals, Proc. Phys. Soc. 60 (1948) 391-394.

[39]R.E. Hoffman, D. Turnbull, Lattice and grain boundary self-diffusion in silver, J. Appl. Phys. 22 (1951) 634-639.

[40]H.V. Atkinson, Theories of normal grain-growth in pure single-phase systems, Acta Metall. 36 (1988) 469-491.

[41]M. Winning, G. Gottstein, L.S. Shvindlerman, Stress induced grain boundary motion, Acta Mater. 49 (2001) 211-219.

[42]F. Mompiou, M. Legros, T. Radetic, U. Dahmen, D.S. Gianola, K.J. Hemker, In situ TEM observation of grain annihilation in tricrystalline aluminum films, Acta Mater. 60 (2012) 2209-2218.

[43]T. Zhu, J. Li, A. Samanta, A. Leach, K. Gall, Temperature and strain-rate dependence of surface dislocation nucleation, Phys. Rev. Lett. 100 (2008) 025502.

[44]M.H. Wu, J.F. Gu, Z.H. Jin, Migration energy barriers of symmetric tilt grain boundaries in body-centered cubic metal Fe, Scripta Mater. 107 (2015) 75-78.

[45]Z.H. Jin et al, Unpublished data.

[46] Y.K. Huang, A.A. Menovsky, F.R. de Boer, Calorimetric analysis of the grain growth in nanocrystalline copper samples, Nanostruct. Mater. 2 (1993) 587-595.

[47]R.J. Asaro, S. Suresh, Mechanistic models for the activation volume and rate sensitivity in metals with nanocrystalline grains and nano-scale twins, Acta Mater. 53 (2005) 3369-3382.

[48]G.L. Wu, D.J. Jensen, In-situ measurement of annealing kinetics of individual bulk grains in nanostructured aluminium, Philos. Mag. 92 (2012) 3381-3391.

[49]M. Winning, In-situ observations of coupled grain boundary motion, Philos. Mag. 87 (2007) 5017-5031.

[50]M. Winning, Motion of $<10$ 0>-tilt grain boundaries, Acta Mater. 51 (2003) 6465-6475.

[51]W.Q. Cao, A. Godfrey, N. Hansen, Q. Liu, Annealing behavior of nanostructured aluminum produced by cold rolling to ultrahigh strains, Metall. Mater. Trans. A 40 (2009) 204-214.

[52]R. Sandström, B. Lehtinen, E. Hedman, I. Groza, S. Karlsson, Subgrain growth in Al and Al-1\% Mn during annealing, J. Mater. Sci. 13 (1978) 1229-1242.

[53]C.Y. Yu, P.L. Sun, P.W. Kao, C.P. Chang, Evolution of microstructure during annealing of a severely deformed aluminum, Mater. Sci. Eng. A 366 (2004) 310-317.

[54]H.W. Zhang, X.X. Huang, R. Pippan, N. Hansen, Thermal behavior of Ni $(99.967 \%$ and $99.5 \%$ purity) deformed to an ultra-high strain by high pressure torsion, Acta Mater. 58 (2010) 1698-1707.

[55] V. Randle, P.R. Rios, Y. Hu, Grain growth and twinning in nickel, Scripta Mater. 58 (2008) 130-133. 
[56]J.H. Cho, J.S. Cho, J.T. Moon, J. Lee, Y.H. Cho, Y.W. Kim, A.D. Rollett, K.H. Oh, Recrystallization and grain growth of cold-drawn gold bonding wire, Metall. Mater. Trans. A 34 (2003) 1113-1125.

[57]A. Takayama, X. Yang, H. Miura, T. Sakai, Continuous static recrystallization in ultrafine-grained copper processed by multi-directional forging, Mater. Sci. Eng. A 478 (2008) 221-228.

[58]R. Dannenberg, E. Stach, J.R. Groza, B.J. Dresser, TEM annealing study of normal grain growth in silver thin films, Thin Solid Films 379 (2000) 133-138.

[59]F. Ebrahimi, H.Q. Li, The effect of annealing on deformation and fracture of a nanocrystalline fcc metal, J. Mater. Sci. 42 (2007) 1444-1454.

[60]M. Legros, D.S. Gianola, K.J. Hemker, In situ TEM observations of fast grain-boundary motion in stressed nanocrystalline aluminum films, Acta Mater. 56 (2008) 3380-3393.

[61]J.A. Sharon, P.C. Su, F.B. Prinz, K.J. Hemker, Stress-driven grain growth in nanocrystalline Pt thin films, Scripta Mater. 64 (2011) 25-28.

[62]Y. Huang, Characteristics of steady state deformation of an Al-0.1 Mg alloy at low temperatures, J. Mater. Sci. 48 (2013) 4484-4491.

[63]C. Zener, Theory of Do for atomic diffusion in metals, J. Appl. Phys. 22 (1951) 372-375.

[64]H. Conrad, Grain-size dependence of the flow stress of $\mathrm{Cu}$ from millimeters to nanometers, Metall. Mater. Trans. A 35 (2004) 2681-2695.

[65]H. Gleiter, The mechanism of grain boundary migration, Acta Metall. 17 (1969) 565-573.

[66]A. Rajabzadeh, F. Mompiou, S. Lartigue-Korinek, N. Combe, M. Legros, D.A. Molodov, The role of disconnections in deformation-coupled grain boundary migration, Acta Mater. 77 (2014) 223-235.

[67]H.A. Khater, A. Serra, R.C. Pond, J.P. Hirth, The disconnection mechanism of coupled migration and shear at grain boundaries, Acta Mater. 60 (2012) 2007-2020.

[68]E.A. Holm, S.M. Foiles, How grain growth stops: a mechanism for grain-growth stagnation in pure materials, Science 328 (2010) 1138-1141.

[69]J.P. Hirth, R.C. Pond, Steps, dislocations and disconnections as interface defects relating to structure and phase transformations, Acta Mater. 44 (1996) 4749-4763.

[70]H. Gleiter, The structure and properties of high-angle grain boundaries in metals, Phys. Status Solidi b 45 (1971) 9-38.

[71]H. Zhang, D.J. Srolovitz, J.F. Douglas, J.A. Warren, Grain boundaries exhibit the dynamics of glass-forming liquids, Proc. Natl. Acad. Sci. U. S. A. 106 (2009) 7735-7740. 


\section{Figure Captions}

Fig. 1. (a) Typical longitudinal section SEM image of the SMGT Cu sample. (b, c, d) Bright-field TEM images at positions B, C and D indicated in (a), respectively. The double-headed arrow in (d) represents the tensile loading direction (the same as in the following Figures).

Fig. 2. True stress-strain curves for the GNG/CG $\mathrm{Cu}$ under uniaxial tensile tests at a constant strain rate of $1 \times 10^{-2} \mathrm{~s}^{-1}$ at $300 \mathrm{~K}$ and $123 \mathrm{~K}$. For comparison, the curves for CG $\mathrm{Cu}$ are also included. All curves are shown up to the point of necking (the same as in the following Figures).

Fig. 3. Bright-field TEM images of the top NG surface layer $(2.5 \mu \mathrm{m}$ below the sample surface) at different deformation temperatures and different strains. (a) $\varepsilon_{\mathrm{T}}=5 \%, 300 \mathrm{~K}$. (b) $\varepsilon_{\mathrm{T}}=25 \%, 300 \mathrm{~K}$. (c) $\varepsilon_{\mathrm{T}}=5 \%, 123 \mathrm{~K}$. (d) $\varepsilon_{\mathrm{T}}=25 \%, 123 \mathrm{~K}$.

Fig. 4. Area-weighted cumulative transversal grain size distributions in the top NG surface layer at different deformation temperatures and different strains.

Fig. 5. True stress-strain curves for the GNG/CG Cu obtained in uniaxial tensile tests at 300 $\mathrm{K}$ but with different strain rates. For comparison, the curves for CG $\mathrm{Cu}$ are also included.

Fig. 6. Bright-field TEM images of the top NG surface layer $(2.5 \mu \mathrm{m}$ below the sample surface) at different strain rates and different strains. (a, b, c) $\varepsilon_{\mathrm{T}}=5 \%, 15 \%, 25 \%, 1 \times 10^{-2}$ $\mathrm{s}^{-1}$. (d, e, f) $\varepsilon_{\mathrm{T}}=5 \%, 15 \%, 25 \%, 1 \times 10^{-5} \mathrm{~s}^{-1}$. 
Fig. 7.(a) Area-weighted cumulative transversal grain size distributions in the top NG surface layer at different strain rates and different strains, as indicated.(b) A mean grain size-normalized cumulative distribution plot for the top NG Cu layer.

Fig. 8. (a) True stress-strain curves for the GNG/CG $\mathrm{Cu}$ and GFG/CG $\mathrm{Cu}$ obtained in uniaxial tensile tests at different temperatures and strain rates. (b) The calculated true stress-strain curves for the top NG Cu layer.

Fig.9. Variation of stress with $d_{\mathrm{t}}^{-1 / 2}$ for the top NG Cu layer at different plastic strains tensioned with different temperatures and strain rates. The different symbols represent the data achieved with different conditions.

Fig.10. Variation of transversal grain size with the loading time for the top NG $\mathrm{Cu}$ layer at different strain rates and temperatures.

Fig. 11. (a) The average grain coarsening rates as afunction ofapplied stresspredicted via Eq. (4) are plotted. (b) The activation energypredicted by Eq. (5) as a function of applied stress. (c) The activation volume as a function of applied stress. The different symbols indicate the yield stress of the NG Cu layer at different tensile conditions. Blue triangle: $123 \mathrm{~K}, 1 \times 10^{-2}$ $\mathrm{s}^{-1}$; red box: $300 \mathrm{~K}, 1 \times 10^{-2} \mathrm{~s}^{-1}$; black circle: $300 \mathrm{~K}, 1 \times 10^{-5} \mathrm{~s}^{-1}$.

Fig. 12. Various grain coarsening rates at different temperatures observed in a number of experiments[13,48-62]. The grain coarsening ratesat low temperature and high temperature are predicated by modified non-diffusionalMott-Turnbull equation (4)and traditionalMott-Turnbull rate equation (2), respectively, as shown by thesolid lines and dotted lines, respectively. 


\section{Depth from surface $(\mu \mathrm{m})$}
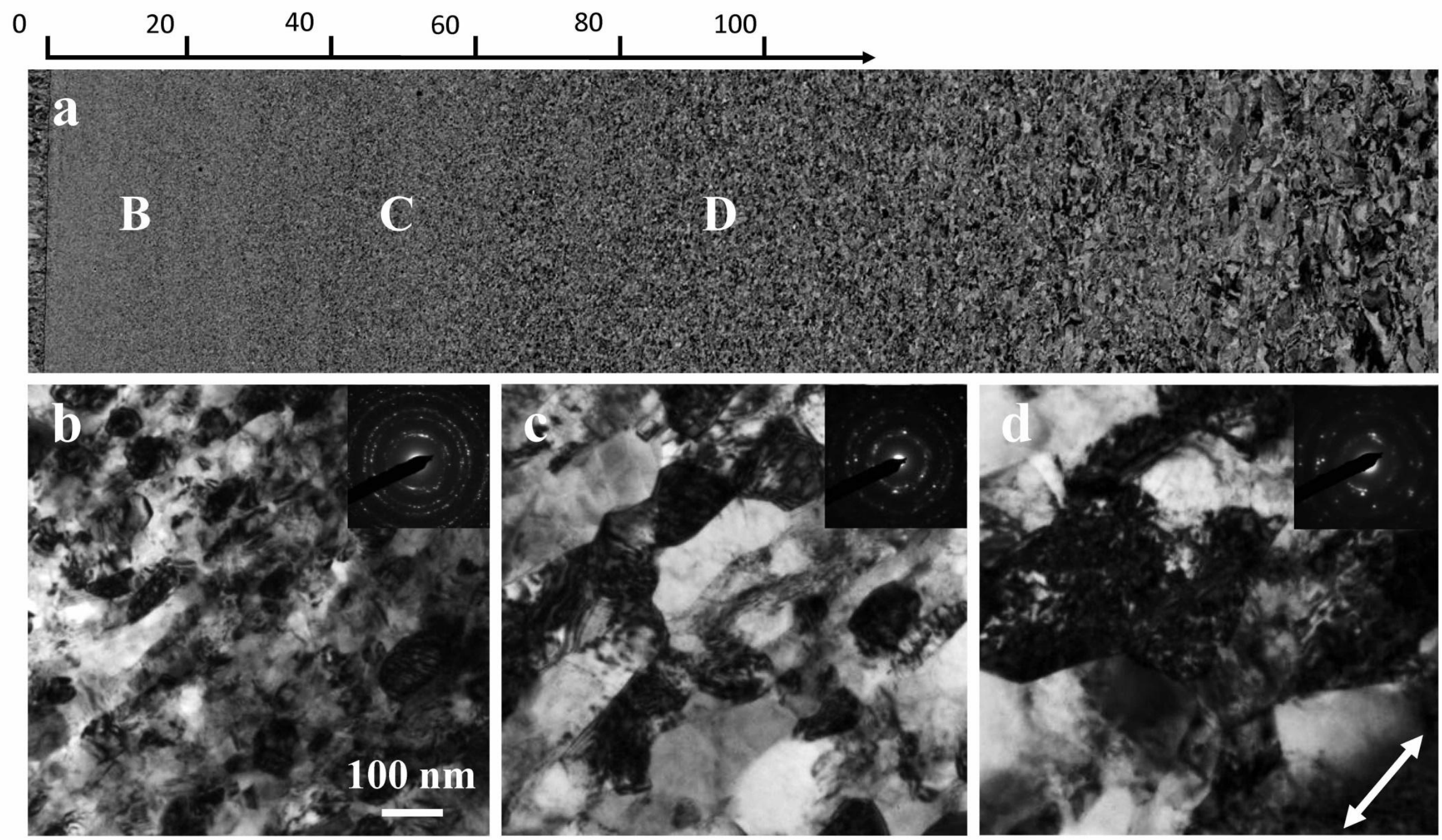

Fig. 1. (a) Typical longitudinal section SEM image of the SMGT Cu sample. (b, c, d) Bright-field TEM images at positions B, C and D indicated in (a), respectively. The double-headed arrow in (d) represents the tensile loading direction (the same as in the following Figures). 


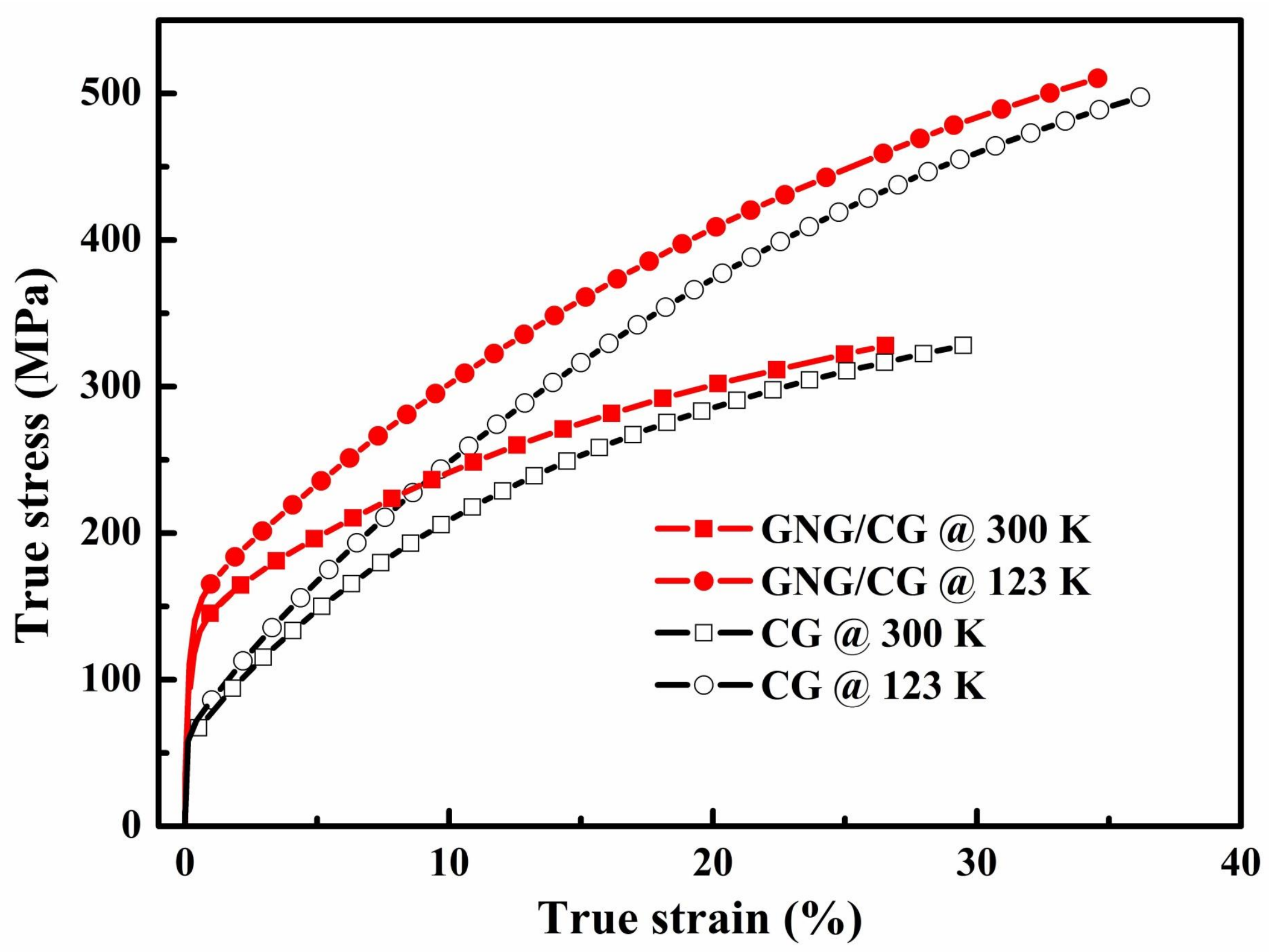

Fig. 2. True stress-strain curves for the GNG/CG $\mathrm{Cu}$ under uniaxial tensile tests at a constant strain rate of $1 \times 10^{-2} \mathrm{~s}^{-1}$ at $300 \mathrm{~K}$ and $123 \mathrm{~K}$. For comparison, the curves for $\mathrm{CG} \mathrm{Cu}$ are also included. All curves are shown up to the point of necking (the same as in the following Figures). 


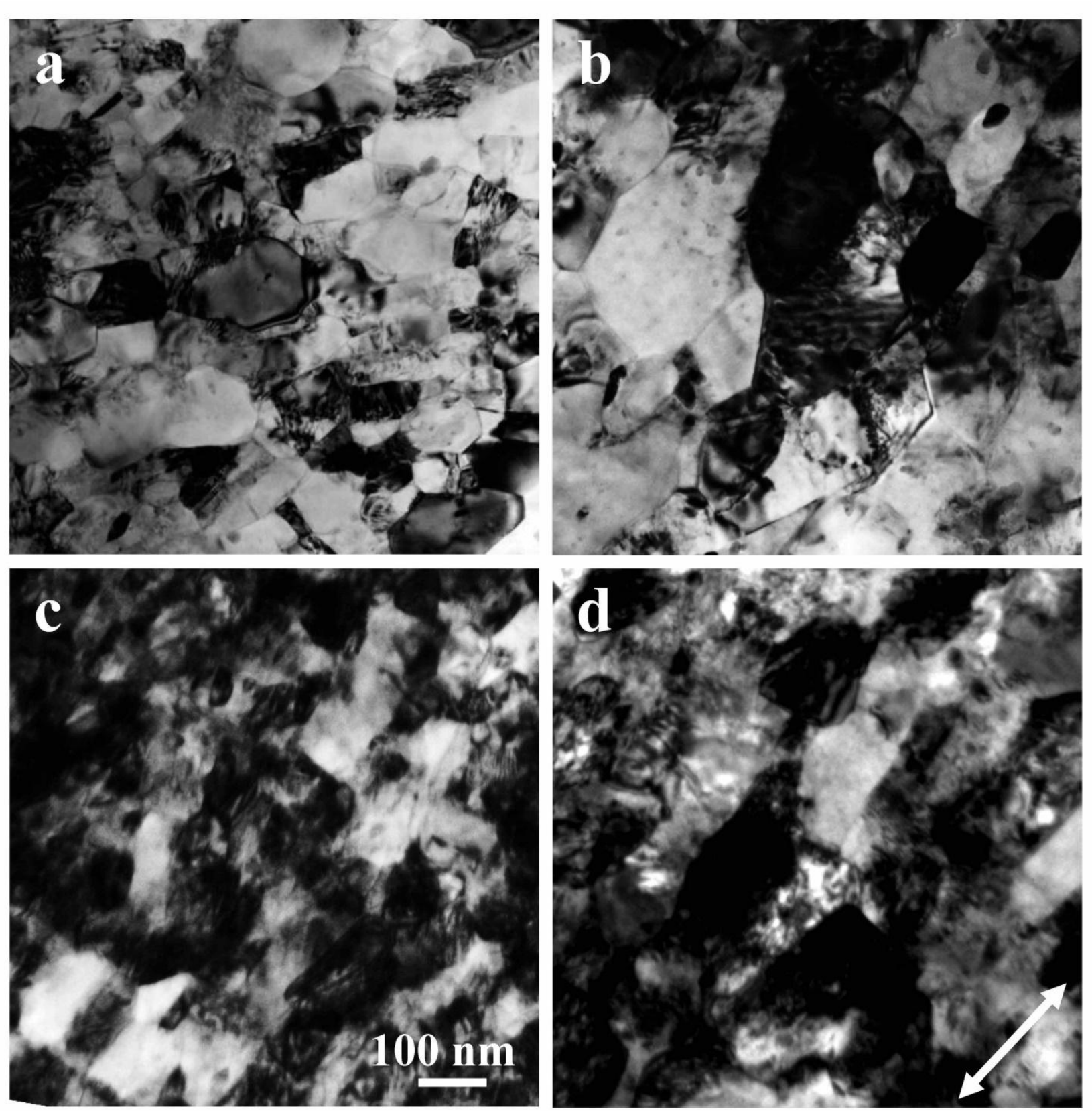

Fig. 3. Bright-field TEM images of the top NG surface layer $(2.5 \mu \mathrm{m}$ below the sample surface) at different deformation temperatures and different strains. (a) $\varepsilon_{\mathrm{T}}=5 \%, 300 \mathrm{~K}$. (b) $\varepsilon_{\mathrm{T}}=25 \%, 300 \mathrm{~K}$. (c) $\varepsilon_{\mathrm{T}}=5 \%, 123 \mathrm{~K}$. (d) $\varepsilon_{\mathrm{T}}=25 \%, 123 \mathrm{~K}$. 


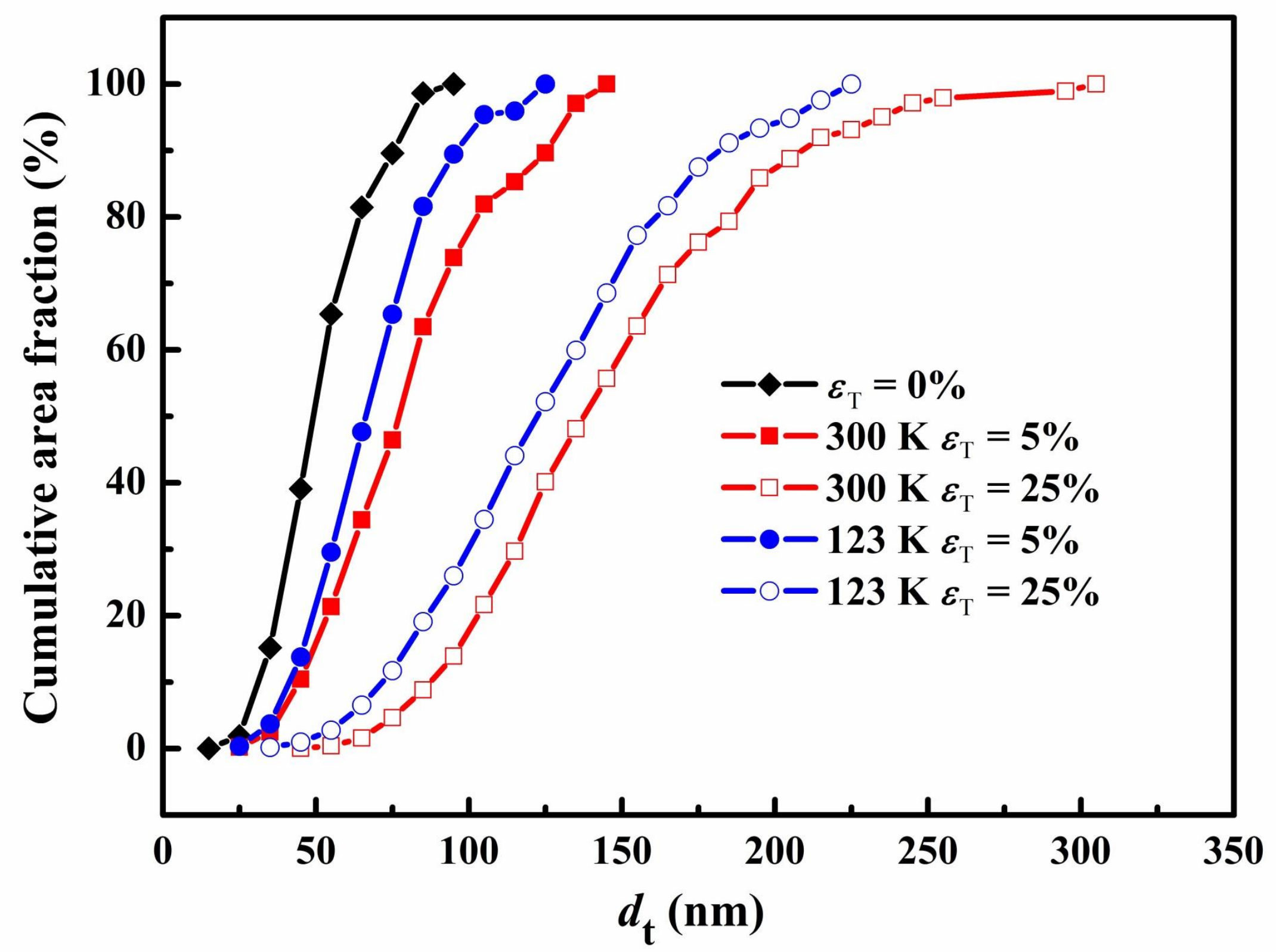

Fig. 4. Area-weighted cumulative transversal grain size distributions in the top NG surface layer at different deformation temperatures and different strains. 


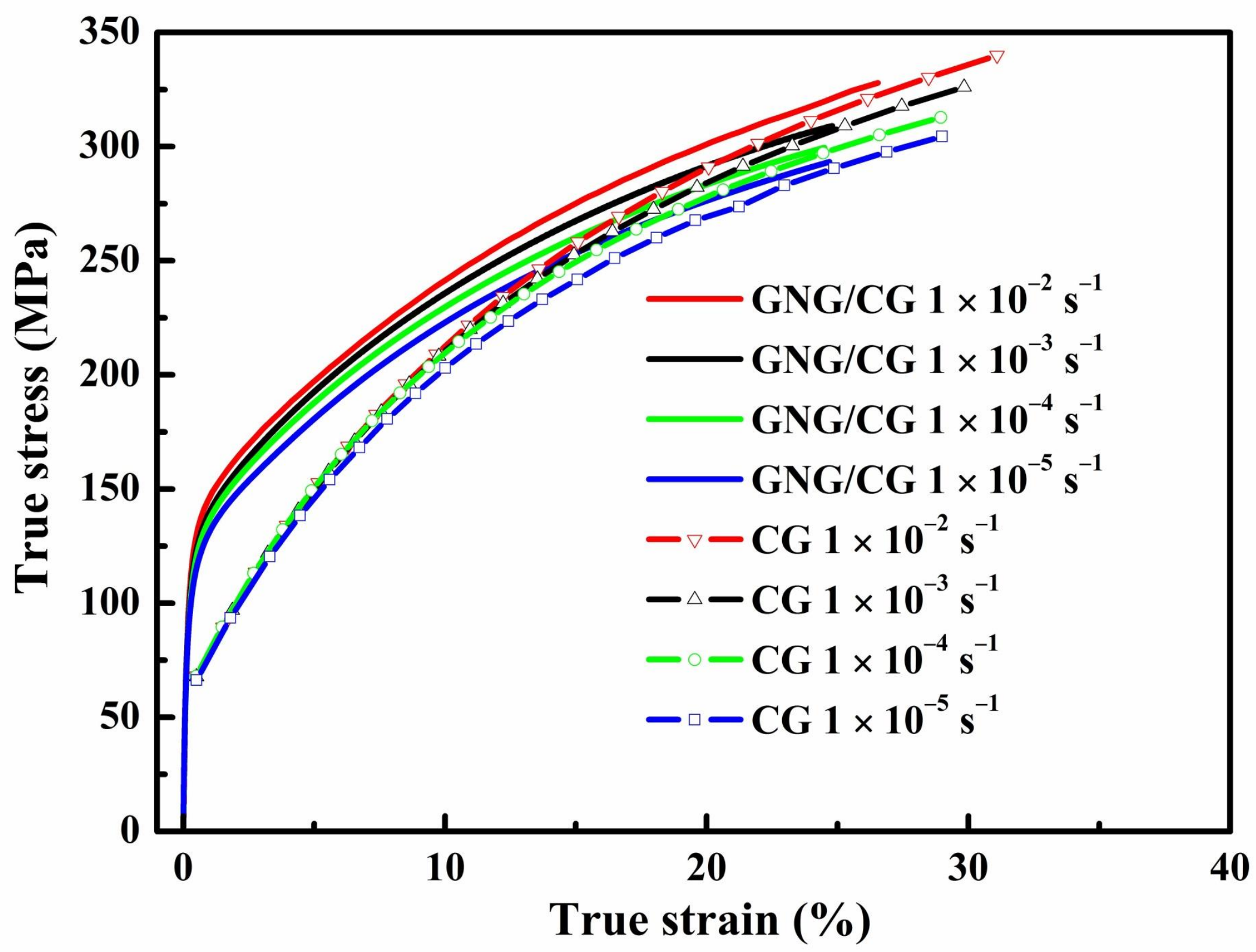

Fig. 5. True stress-strain curves for the GNG/CG Cu obtained in uniaxial tensile tests at $300 \mathrm{~K}$ but with different strain rates. For comparison, the curves for $\mathrm{CG} \mathrm{Cu}$ are also included. 

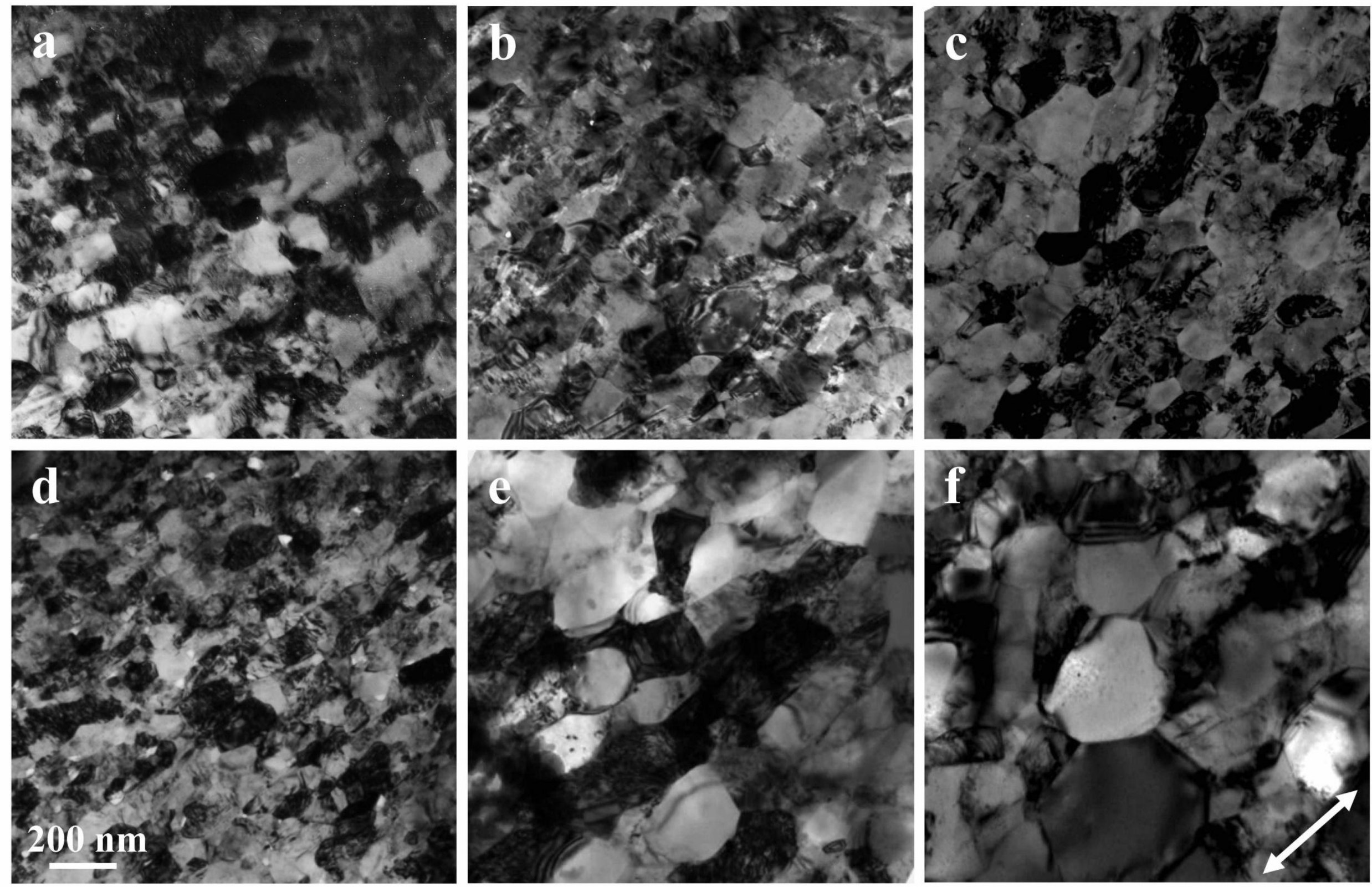

Fig. 6. Bright-field TEM images of the top NG surface layer $(2.5 \mu \mathrm{m}$ below the sample surface $)$ at different strain rates and different strains. $(\mathrm{a}, \mathrm{b}, \mathrm{c}) \varepsilon_{\mathrm{T}}=5 \%, 15 \%, 25 \%, 1 \times 10^{-2} \mathrm{~s}^{-1}$. (d, e, f) $\varepsilon_{\mathrm{T}}=5 \%$, $15 \%, 25 \%, 1 \times 10^{-5} \mathrm{~s}^{-1}$ 

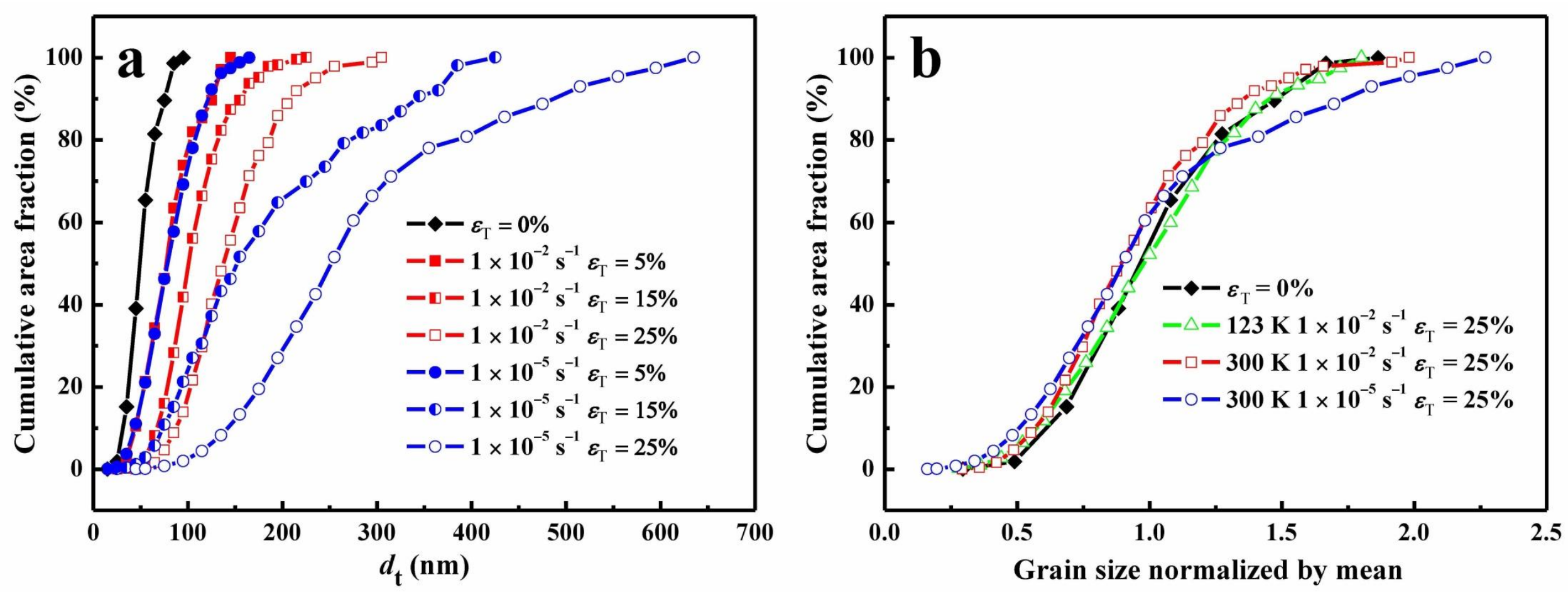

Fig. 7. (a) Area-weighted cumulative transversal grain size distributions in the top NG surface layer at different strain rates and different strains, as indicated. (b) A mean grain size-normalized cumulative distribution plot for the top NG Cu layer. 

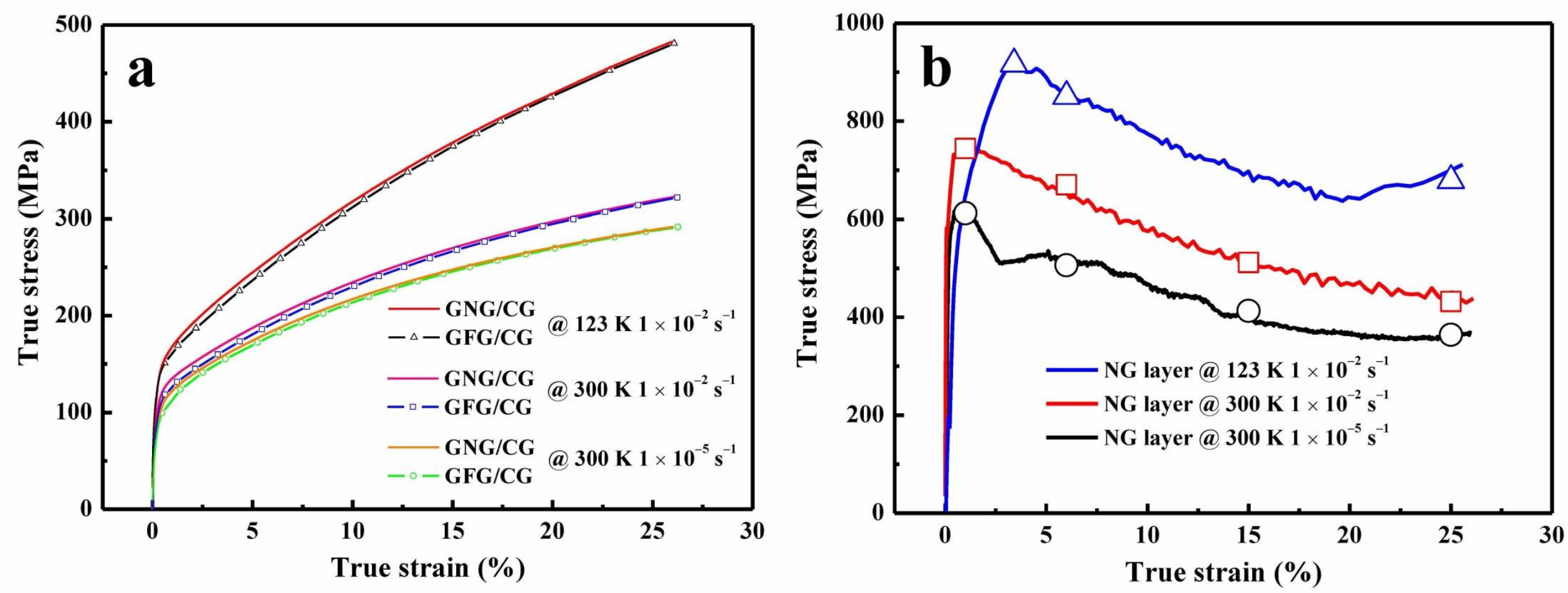

Fig. 8. (a) True stress-strain curves for the GNG/CG Cu and GFG/CG $\mathrm{Cu}$ obtained in uniaxial tensile tests at different temperatures and strain rates. (b) The calculated true stress-strain curves for the top NG Cu layer. 


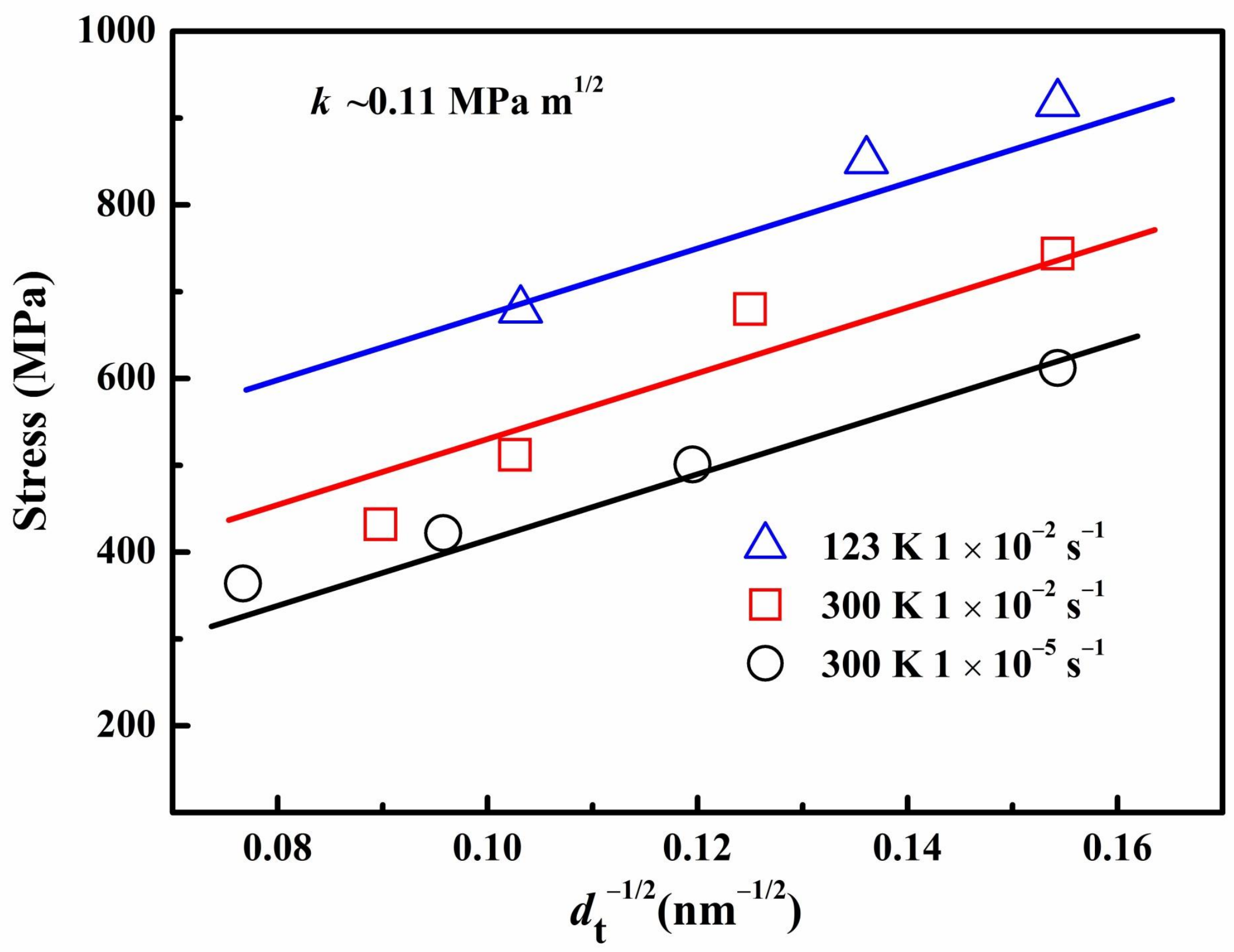

Fig. 9. Variation of stress with $d_{\mathrm{t}}^{-1 / 2}$ for the top $\mathrm{NG} \mathrm{Cu}$ layer at different plastic strains tensioned with different temperatures and strain rates. The different symbols represent the data achieved with different conditions. 


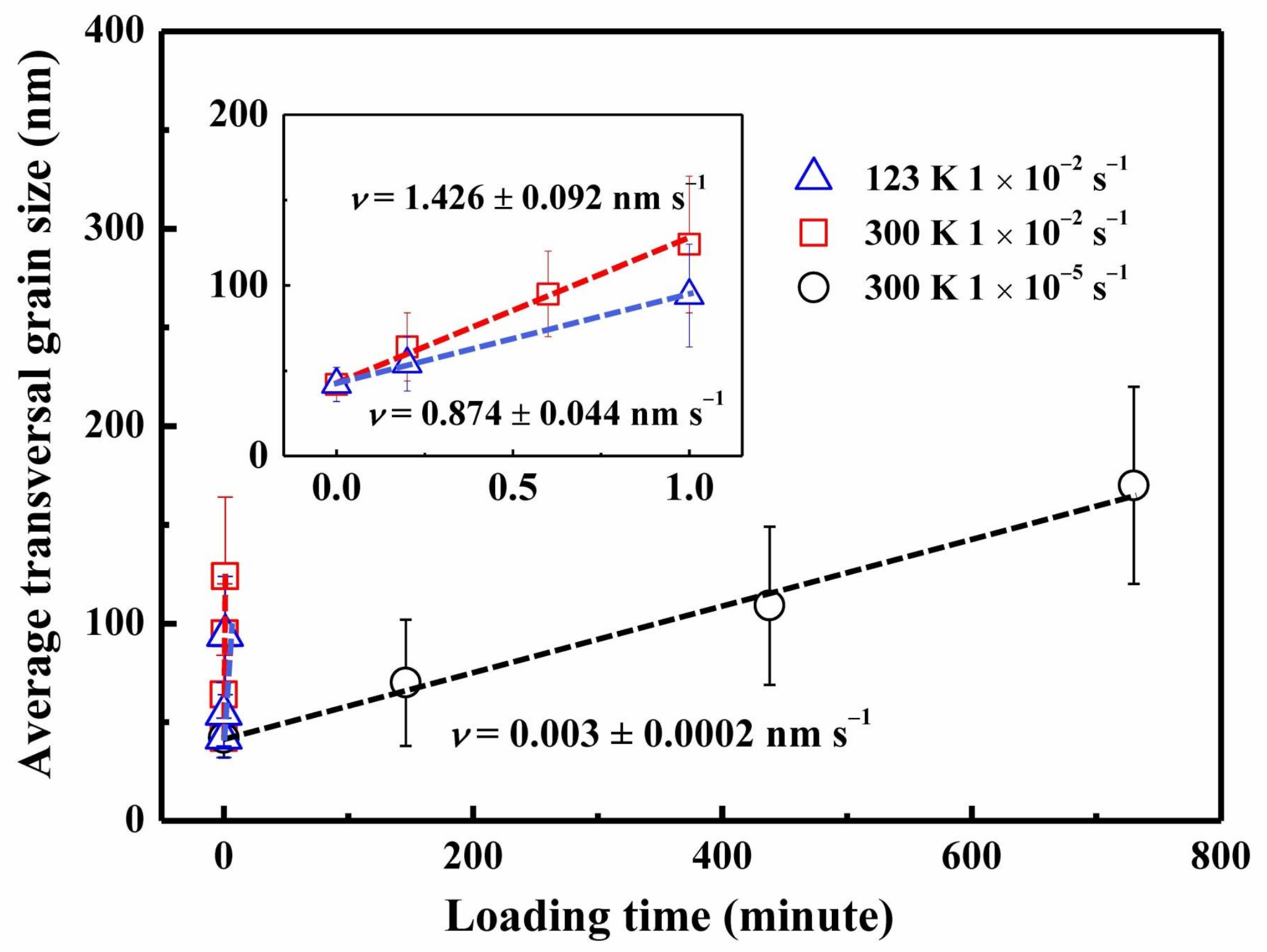

Fig. 10. Variation of transversal grain size with the loading time for the top $\mathrm{NG} \mathrm{Cu}$ layer at different strain rates and temperatures. 


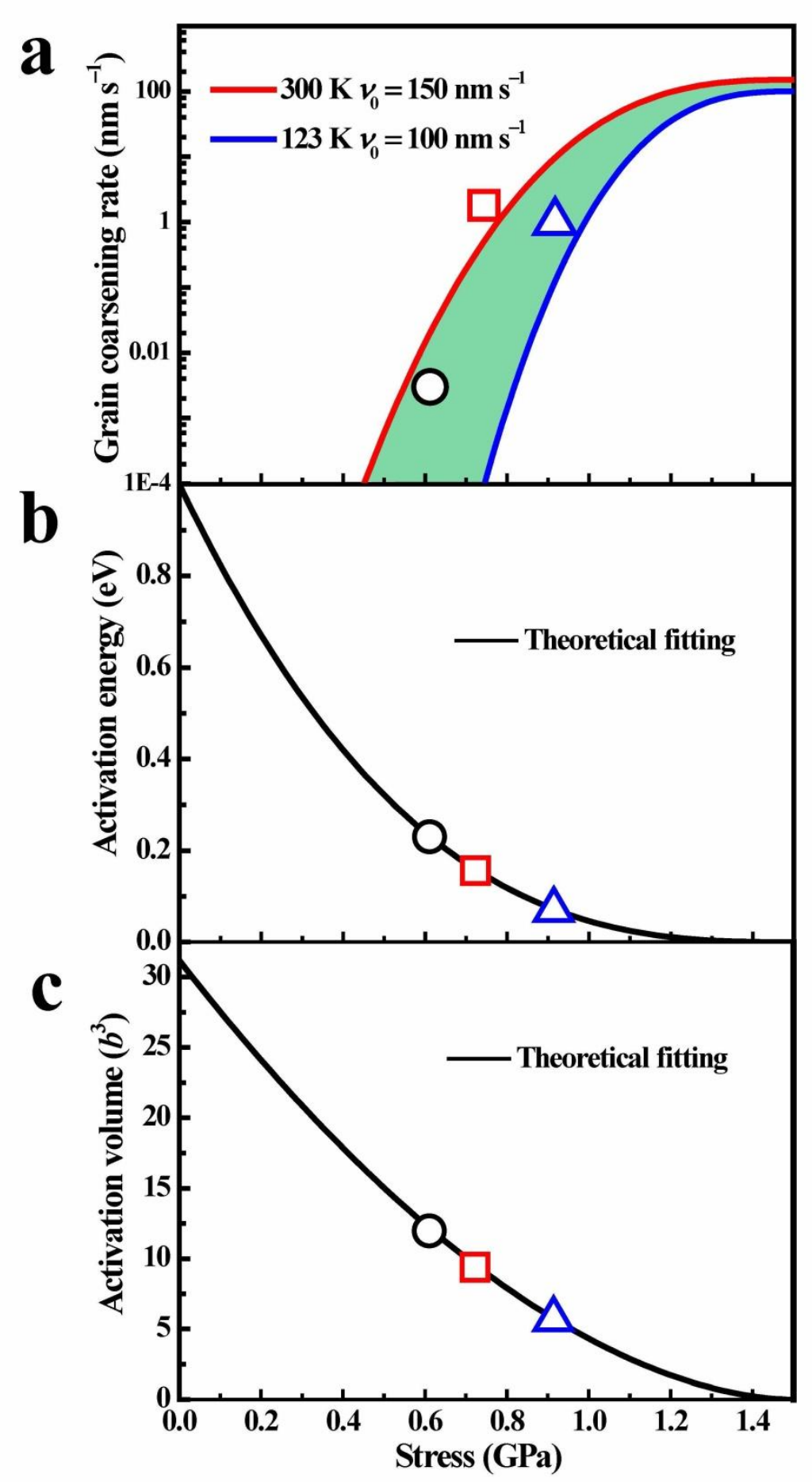

Fig. 11. (a) The average grain coarsening rates as a function of applied stress predicted via Eq. (4) are plotted. (b) The activation energy predicted by Eq. (5) as a function of applied stress. (c) The activation volume as a function of applied stress. The different symbols indicate the yield stress of the NG $\mathrm{Cu}$ layer at different tensile conditions. Blue triangle: $123 \mathrm{~K}, 1$ $\times 10^{-2} \mathrm{~s}^{-1}$; red box: $300 \mathrm{~K}, 1 \times 10^{-2} \mathrm{~s}^{-1}$; black circle: $300 \mathrm{~K}, 1 \times 10^{-5} \mathrm{~s}^{-1}$. 


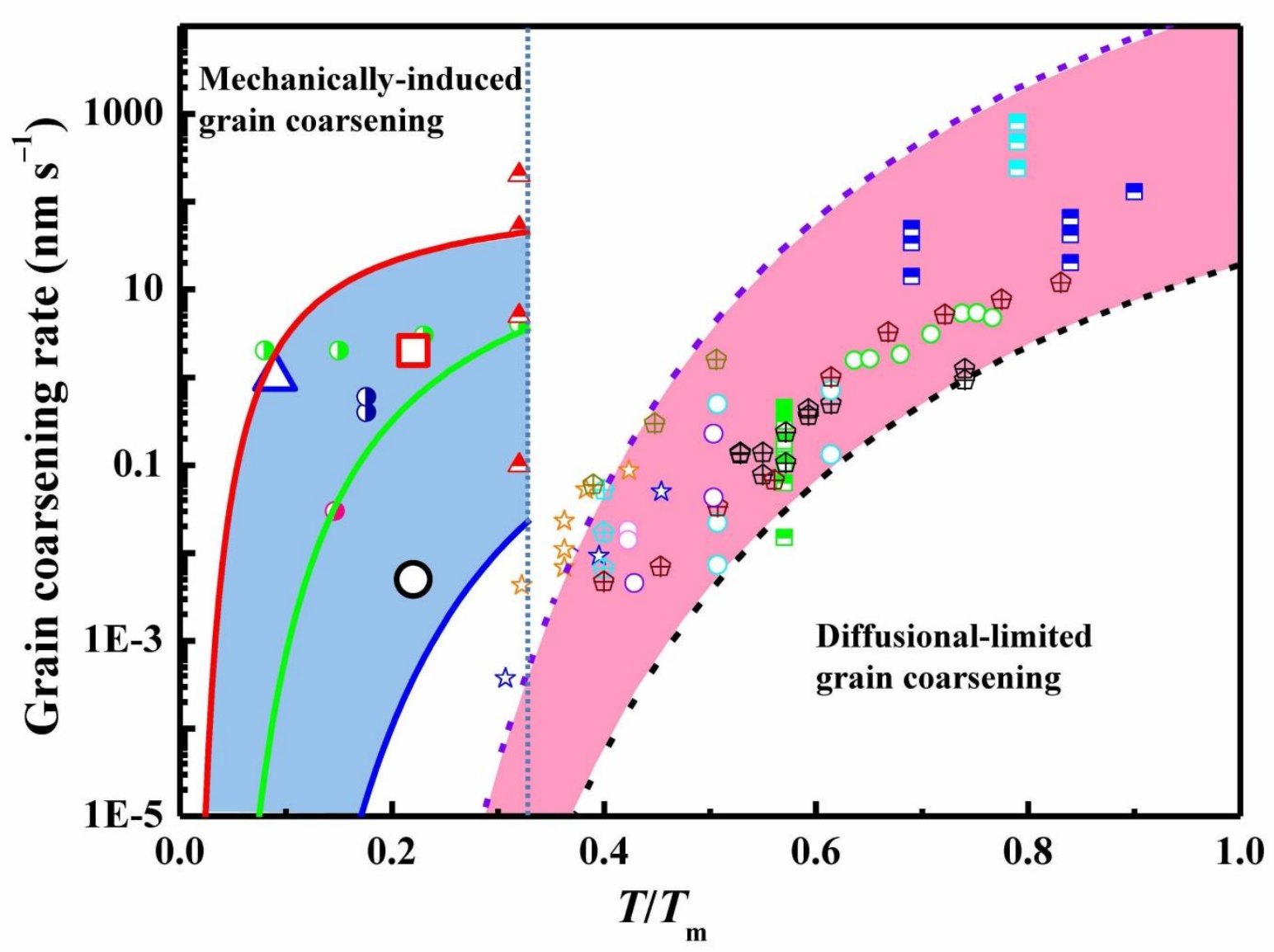

$$
\begin{aligned}
& \sigma=1 \mathrm{GPa} v_{0}=150 \mathrm{~nm} \mathrm{~s}^{-1} \\
& \sigma=0.75 \mathrm{GPa} v_{0}=150 \mathrm{~nm} \mathrm{~s}^{-1} \\
& \sigma=0.5 \mathrm{GPa} v_{0}=100 \mathrm{~nm} \mathrm{~s}^{-1} \\
& \cdots \sigma=0 \mathrm{GPa} v_{0}=10^{8} \mathrm{~nm} \mathrm{~s}^{-1} \\
& \cdots \sigma=0 \text { GPa } v_{0}=10^{5} \mathrm{~nm} \mathrm{~s}^{-1} \\
& \triangle \quad \square \quad O \quad \text { this study } \\
& \text { - Al [48] O Au [56] } \\
& \text { - } \mathrm{Al}[49] \quad \mathrm{Cu}[57] \\
& \text { - } \mathrm{Al}[50] \text { is } \mathrm{Ag}[58] \\
& \oplus \mathrm{Al}[51] \text { « Ni-Fe [59] } \\
& \oplus \mathrm{Al}[52] \quad \Delta \mathrm{Al}[60] \\
& \oplus \mathrm{Al}[53] \text { • } \mathrm{Pt}[61] \\
& \oplus \mathrm{Ni}[54] \odot \mathrm{Al}[62] \\
& \text { - } \mathrm{Ni}[55] \text { - Ni-Fe [13] }
\end{aligned}
$$

Fig. 12. Various grain coarsening rates at different temperatures observed in a number of experiments $[13,48-62]$. The grain coarsening rates at low temperature and high temperature are predicated by modified non-diffusional Mott-Turnbull equation (4) and traditional Mott-Turnbull rate equation (2), respectively, as shown by the solid lines and dotted lines, respectively. 

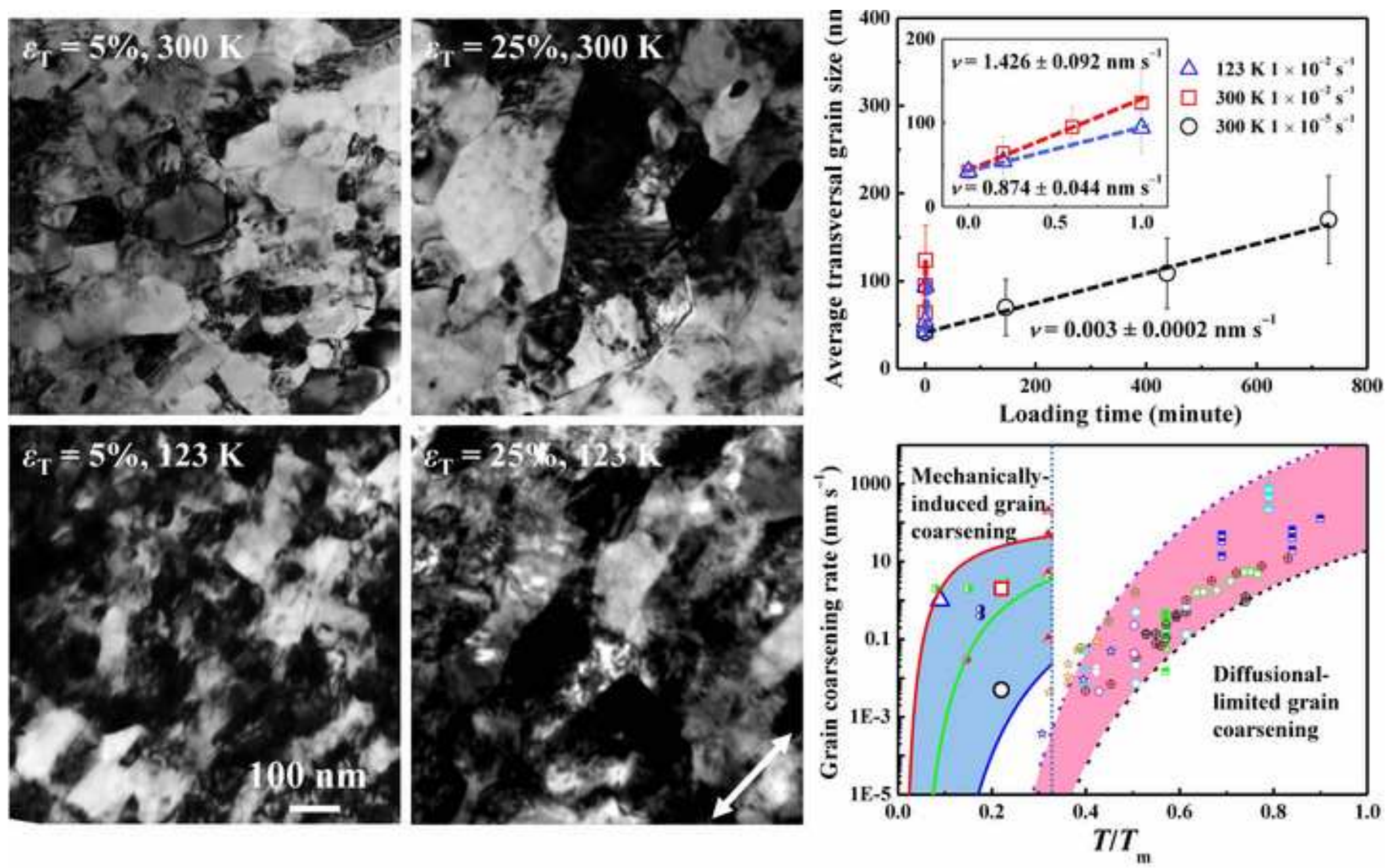